\title{
Additional Evidence to Support the Use of Noninvasive Ventilation in Asthma Exacerbation
}

Noninvasive ventilation (NIV) has become a standard of care for patients with exacerbation of COPD and cardiogenic pulmonary edema. Studies have also sought to determine the effectiveness of NIV in exacerbation of asthma. Studies have investigated radioaerosol particle distribution to help explain the effects of NIV in normals and in those with asthma. In addition, NIV has been combined with nebulization of bronchodilators and other drugs, and a multitude of studies have looked into the variables involved with nebulization during NIV, with resultant recommendations.

See the Original Study on Page 241

In this issue, a study by Galindo-Filho et al reveals the effects of nebulization with and without NIV in patients with asthma. ${ }^{1}$ They wanted to assess the effects of coupling $\beta$ agonist nebulization and NIV during asthma exacerbations on radioaerosol pulmonary deposition using scintigraphy and on cardiopulmonary parameters, and the correlation of pulmonary function with radioaerosol deposition index, radioaerosol penetration index, and pulmonary clearance. The study included 21 patients with asthma exacerbation, $\mathrm{FEV}_{1}<60 \%$ predicted, breathing frequency $>25$ breaths/min, and current asthma attack lasting $<7$ days. The 2 groups consisted of those patients receiving a radioaerosol bronchodilator nebulizer treatment alone $(n=11)$, and those receiving a radioaerosol bronchodilator nebulizer treatment via NIV $(n=10)$. In the NIV group, the nebulizer was positioned between the mask and the leak orifice. The nebulizer was powered with oxygen at $7 \mathrm{~L} / \mathrm{min}$, for $9 \mathrm{~min}$. In the NIV group, the inspiratory pressure was set at $12 \mathrm{~cm} \mathrm{H}_{2} \mathrm{O}$ and the expiratory pressure at $5 \mathrm{~cm} \mathrm{H}_{2} \mathrm{O}$. The breathing frequency, tidal volume, and minute volume decreased in the NIV + nebulizer group. Spirometry values increased, but not significantly. There was no change in radioaerosol deposition between groups. The authors concluded that an inspiratory flow of $>30 \mathrm{~L} / \mathrm{min}$ during NIV may have influenced an upper lobe and central distribution of particles, and changes in breathing frequency, tidal volume, and minute ventilation were due to an additive effect of positive pressure in addition to the presence of $\beta$ adrenergic bronchodilators.
The Galindo-Filho study prompts several questions, such as:

- Is NIV effective in improving outcomes in patients with an asthma attack?

- Is nebulization effective during NIV?

- Is nebulization effective during NIV in patients with an asthma attack?

- Is nebulization effective during NIV in exacerbation of other pulmonary diseases?

\section{NIV During Asthma Attack}

Is NIV appropriate for the treatment of patients with severe asthma attacks who may otherwise require intubation? In a 2010 study, Murase and colleagues ${ }^{2}$ considered NIV in 54 patients in respiratory distress with mild to moderate asthma, as defined by the Global Initiative for Asthma. ${ }^{3}$ They compared their findings to a historical control of 48 patients with the same inclusion criteria. In the control group, 9 patients were intubated and none were started on NIV, whereas in the NIV eligible group, 2 were intubated and 17 patients received NIV $(P<.001)$. Among the NIV group there was a significant decrease in hospital stay $(P<.01)$ and in the ICU or intermediate care $(P=.03)$, compared to the historical control. The duration of ventilation tended to be less in the NIV group than in those who were intubated $(P=.09)$. The rate of intubation for patients with severe asthma attack was significantly reduced after the introduction of NIV, and the introduction of NIV was strongly associated with a reduction in the number of patients requiring intubation. NIV was implemented early in the course of the asthma attack, and was credited with these positive outcomes. The authors also speculated that NIV gave patients time to respond to other conventional treatments, such as corticosteroids and $\beta$ agonists. Several other studies reviewed below have accepted NIV as effective during asthma.

\section{NIV and Nebulization}

Methodological issues in nebulization during NIV have been the topic of many studies. Optimal nebulizer position 
has been determined to be between the leak port and patient connection to the mask, with higher breathing frequencies (20 breaths/min) and inspiratory pressures (15$\left.25 \mathrm{~cm} \mathrm{H}_{2} \mathrm{O}\right)$, and a high expiratory pressure $\left(10 \mathrm{~cm} \mathrm{H}_{2} \mathrm{O}\right.$ vs $5 \mathrm{~cm} \mathrm{H}_{2} \mathrm{O}$ ), significantly increasing albuterol delivery in a lung model. As much as $25 \%$ of the nominal dose of albuterol was delivered with these ventilatory parameters. ${ }^{4}$ In another in vitro study it was determined that during NIV $\left(15 / 5 \mathrm{~cm} \mathrm{H}_{2} \mathrm{O}\right)$ more aerosolized medication was delivered to a filter when the leak port was in the circuit, rather than in the mask. Aerosol deposition varied with the brandname of mask, as one mask had a leak port incorporated and the other did not, so the leak was in the single-tube ventilator circuit. ${ }^{5}$ In the previous study by this group, both tidal volume and inspiratory flow (up to $30 \mathrm{~L} / \mathrm{min}$ with spontaneous breathing) were increased, resulting in an increase in radioaerosol deposition in the lung. However, the increase is not as much with NIV, because the flow is greater $(40 \mathrm{~L} / \mathrm{min})$, resulting in more central radioaerosol deposition. With both spontaneous breathing and NIV, radioaerosol deposition was greatest in the middle and lower regions of both lungs. Therefore, peak flow during NIV has an impact on aerosol distribution. As flow increases, radioaerosol deposition in the periphery is less than centrally. ${ }^{6}$ This is described in the present study.

The factors affecting aerosol deposition during NIV are many and are related to the type of ventilator used, the type of circuit used, the nature of added humidification, the physical characteristics of the medication, the ventilator's breathing parameters (in particular, flow, as described in the present paper), type of interface, type of nebulizer, and the nature of the patient's disease and severity. These factors are extensively reviewed and are summarized in the Table, which is a technique for using a small-volume nebulizer during NIV. ${ }^{7}$ Nebulization is effective during NIV, especially when supported by the evidence. $^{7}$

\section{NIV and Asthma and Nebulization}

Several papers have been published on the combination of NIV, asthma, and nebulization, in addition to the present paper. In their review of the use of bronchodilators during NIV, Ceriana et al studied the evidence that there is a beneficial effect of NIV or pressure support ventilation with PEEP in asthma exacerbations. It decreases the work of breathing and facilitates the bronchodilator effects of $\beta$ adrenergic drugs. NIV-driven aerosols were associated with a quicker and greater improvement of peak expiratory flow. ${ }^{8}$

In an older study in 100 patients with mild-moderate asthma exacerbation upon admission to the emergency department, Pollack et al administered albuterol either by small-volume nebulizer or by NIV of $10 / 5 \mathrm{~cm} \mathrm{H}_{2} \mathrm{O}$.
Table. Technique for Using a Small-Volume Nebulizer During Noninvasive Ventilation

Assess patient, especially hemodynamic status, mask fit and tolerability, and patient-ventilator synchrony.

Minimize leaks in the mask and/or circuit (although newer ventilators compensate for leaks).

Fill nebulizer up to optimal fill volume (4-6 $\mathrm{mL}$ for a jet nebulizer).

Place nebulizer upright between air leak in circuit and mask.

Select modest level of CPAP $\left(\sim 5 \mathrm{~cm} \mathrm{H}_{2} \mathrm{O}\right)$ and inspiratory pressure support $\left(10-15 \mathrm{~cm} \mathrm{H}_{2} \mathrm{O}\right)$.

Humidify inspired air if patient is receiving noninvasive ventilation for $>30 \mathrm{~min}$.

Operate nebulizer with gas flow of 6-8 L/min.

Tap nebulizer periodically, until it sputters.

Monitor patient and assess clinical response.

Remove nebulizer from circuit, rinse with sterile water, air dry, and store in a clean space.

Reconnect circuit.

Observe patient for any adverse effects

(From Reference 7, with permission.)

Following this therapy, peak flow was higher in those patients who received their aerosols via NIV $(P<.001)$. This response may be explained by a pressure support effect, an enhanced drug delivery effect, or a combination of these. ${ }^{9}$ This is similar to the effect of intermittent positive-pressure breathing on drug delivery, in that aerosol drug delivery is enhanced by intermittent positive-pressure breathing in those patients unable to take effective deep breaths. However, the breathing pattern in intermittent positive-pressure breathing is not the same as in NIV. Soroksky et al reported that administration of bronchodilators during NIV resulted in a decreased breathing frequency and improved spirometry $(P=.006)$, more than jet nebulizer alone. NIV was set to an inspiratory pressure of $8-15 \mathrm{~cm} \mathrm{H}_{2} \mathrm{O}$ and an expiratory pressure of $3-5 \mathrm{~cm} \mathrm{H}_{2} \mathrm{O}$. Other end points were reduced need for hospitalization $(P=.01)$ and faster alleviation of the attack. ${ }^{10}$

Likewise, in 36 asthma patients in the $\mathrm{ED}$, Brandão et al reported that with NIV $\left(15 / 10 \mathrm{~cm} \mathrm{H}_{2} \mathrm{O}\right), \mathrm{FVC}, \mathrm{FEV}_{1}$, and peak expiratory flow improved, more than with NIV 15/ $5 \mathrm{~cm} \mathrm{H}_{2} \mathrm{O} . \mathrm{FEV}_{1}$ improved from $38 \%$ to $53 \%(P=.03)$ and peak expiratory flow improved from $22 \%$ to $43 \%$ $(P=.03)$ with NIV of $15 / 10 \mathrm{~cm} \mathrm{H}_{2} \mathrm{O}$, due to improved alveolar recruitment with a higher expiratory pressure, which may improve patency of peripheral airways and collateral pulmonary ventilation. The lower change in pressure in the $15 / 10 \mathrm{~cm} \mathrm{H}_{2} \mathrm{O}$ group also likely favored laminar flow, which would contribute to better deposition. When associated with NIV, nebulization appears to open airways and, in turn, areas of atelectasis. The failure of SVN has been attributed to inadequate deposition of medication, which the present study examines. ${ }^{11}$ 


\section{Additional Evidence to Support the Use of Noninvasive Ventilation in Asthma Exacerbation}

Finally, Gupta et al reported that in a group of 53 asthmatics, application of NIV reduced ICU and hospital stay $(P=.01)$ and decreased the mean dose of bronchodilators needed for symptom relief $(P=.007$ for ipratropium, $P=.008$ for albuterol). $\mathrm{FEV}_{1}$ improved similarly in both groups. ${ }^{12}$ The present paper and others cited here support the effectiveness of nebulization during NIV in patients with asthma.

\section{NIV and Other Obstructive Airway Diseases and Nebulization}

Most of the literature supporting NIV concerns its use in exacerbation of COPD. Mukhopadhyay et al reported that short-term cessation ( $\sim 10 \mathrm{~min})$ of NIV for nebulization of albuterol did not result in distress, discomfort, or physiologic instability in 19 patients with COPD. Researchers looked at accessory muscle use, dyspnea, heart rate, breathing frequency, blood pressure, and arterial blood gases. There were no clinically important decreases in saturation, or increases in heart rate or systolic blood pressure. There were no statistically significant differences in diastolic blood pressure, breathing frequency, Borg score, $\mathrm{pH}$, $\mathrm{P}_{\mathrm{aCO}}, \mathrm{P}_{\mathrm{aO}_{2}}$, or tidal volume. This was a small study and the authors recommended close patient supervision while NIV is suspended for nebulization. ${ }^{13}$

The effect of pressure support ventilation on deposition of aerosolized drugs in children with cystic fibrosis was studied. Using a radio-labeled substance, researchers found a $30 \%$ increase in absolute radioactivity in the lungs with $8-10 \mathrm{~cm} \mathrm{H}_{2} \mathrm{O}$ pressure support ventilation. This was attributed to a favorable breathing pattern (increased tidal volume and decreased breathing frequency) induced by pressure support ventilation. ${ }^{14}$

\section{Summary}

There is no doubt that NIV is effective in the care of patients with obstructive lung disease. It improves arterial blood gases, relieves dyspnea, and improves the delivery of medications such as bronchodilators, which are the cornerstone for therapy for these disorders. The current study adds to our knowledge of NIV in asthma by demonstrating that a flow of $>30 \mathrm{~L} / \mathrm{min}$ results in a more central and upper lobe distribution of aerosol, and changes in breathing frequency, tidal volume, and minute ventilation are

The author has disclosed no conflicts of interest.

Correspondence: Timothy B Op't Holt EdD RRT AE-C FAARC, Department of Cardiorespiratory Care, University of South Alabama, 5721 USA Drive North, Mobile AL 36688-0002. E-mail: toptholt@ southalabama.edu.

DOI: $10.4187 /$ respcare.02314 due to an additive effect of positive pressure in addition to the presence of $\beta$ adrenergic bronchodilators. Patients with exacerbation of asthma in whom NIV is initiated need to be monitored closely for signs of the success or failure of NIV, and nebulization of $\beta$ agonists is supported by the literature.

Timothy B Op't Holt EdD RRT AE-C FAARC Department of Cardiorespiratory Care University of South Alabama

Mobile, Alabama

\section{REFERENCES}

1. Galindo-Filho VC, Brandão DC, Ferreira R de CS, Menezes MJC, Almeida-Filho P, Parreira VF, et al. Noninvasive ventilation coupled with nebulization during asthma crises: a randomized controlled trial. Respir Care 2013;58(2):241-249.

2. Murase K, Tomii K, Chin K, Tsuobi T, Sakurai A, Tachikawa R, et al. The use of noninvasive ventilation for life-threatening asthma attacks: changes in the need for intubation. Respirology 2010;15(4): 714-720.

3. Global Initiative for Asthma (GINA). Global strategy for asthma management and prevention, December 2011. http://www.goldcopd. org/guidelines-global-strategy-for-diagnosis-management.html. Accessed November 30, 2012.

4. Chatmongkolchart S, Schettino GP, Dillman C, Kacmarek RM, Hess DR. In-vitro evaluation of aerosol bronchodilator delivery during noninvasive positive pressure ventilation: effect of ventilator settings and nebulizer position. Crit Care Med 2002;30(11):2515-2519.

5. Branconnier MP, Hess DR. Aerosol delivery during noninvasive ventilation. Respir Care 2005;50(12):1649-1653

6. França EE, Dornelas de Andrade AF, Cabral G, Almeida Filho P, Silva KC, Galindo Filho VC, et al. Nebulization associated with bilevel noninvasive ventilation: analysis of pulmonary radioaerosol deposition. Respir Med 2006;100(4):721-728.

7. Dhand R. Aerosol therapy in patients receiving noninvasive positive pressure ventilation. J Aerosol Med Pulm Drug Deliv 2012;25(2):63-78.

8. Ceriana P, Navalesi P, Rampulla, Prinianakis G, Nava S. Use of bronchodilators during non-invasive ventilation. Monaldi Arch Chest Dis 2003;59(2):123-127.

9. Pollack CV, Fleisch KB, Dowsey K. Treatment of acute bronchospasm with beta adrenergic aerosols delivered by a nasal bilevel positive airway pressure circuit. Ann Emerg Med 1995;26(5):552557.

10. Soroksky A, Stav D, Shpirer I. A pilot prospective, randomized, placebo controlled trial of bilevel positive pressure in acute asthmatic attack. Chest 2003;123(4):1018-1025.

11. Brandão DC, Lima VM, Filho VG, Silva TS, Campos TF, Dean E, de Andrade AD. Reversal of bronchial obstruction with bilevel positive airway pressure and nebulization in patients with acute asthma. J Asthma 2009;46(4):356-361.

12. Gupta D, Nath A, Agarwal R, Behera D. A prospective, randomized controlled trial on the efficacy of noninvasive ventilation in severe acute asthma. Respir Care 2010;55(5):536-543.

13. Mukhopadhyay A, DelaPena E, Wadden B, Procyshyn M, Lim TK. Effects of inhalational bronchodilator treatment during noninvasive ventilation in severe chronic obstructive pulmonary disease exacerbations. J Critical Care 2009;24,474.e1-e474.e5.

14. Fauroux B, Itti E, Pigeot J, Isabey D, Meignan M, Ferry G, et al. Optimization of aerosol deposition by pressure support in children with cystic fibrosis. Am J Respir Crit Care Med 2000;162(6):22652271. 